\title{
14
}

\section{Nanotechnology Research and Science, Technology, and Society Education at Bilkent University}

\author{
Haldun M. Ozaktas
}

\section{CONTENTS}

Nanotechnology Research Activities at Bilkent University and in Turkey

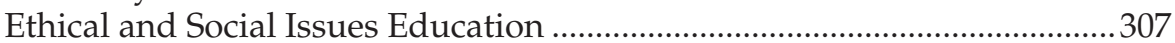

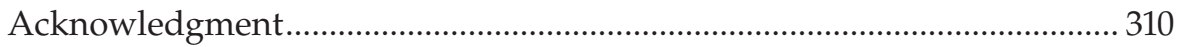

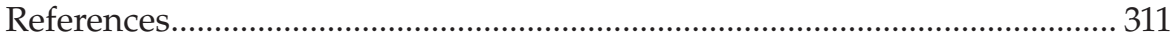

KEY WORDS: nanoscience; nanotechnology; research centers; research funding; engineering ethics; science, technology, and society; community research; Bilkent University; Turkey

\section{Nanotechnology Research Activities at Bilkent University and in Turkey}

Bilkent University was established in Ankara in 1984 as the first private nonprofit university in Turkey. It was able to quickly attract high-quality faculty and students, and shortly became one of the leading universities of Turkey. It presently ranks first in Turkey, 32nd in Europe, and 112th worldwide in the Times Higher Education rankings. Presently it has nine faculties, several vocational schools, and around 12,000 students (Bilkent University, 2011a).

The university has particular strength in physical sciences and engineering. It is the home of several nanotechnology research centers.

The Advanced Research Laboratories (ARL) was built in 1992 and equipped with a grant from the Ministry of Defence. ARL is a multidisciplinary laboratory with researchers from different backgrounds and is open to researchers throughout Turkey. Photonic gap materials, metamaterials, compound 


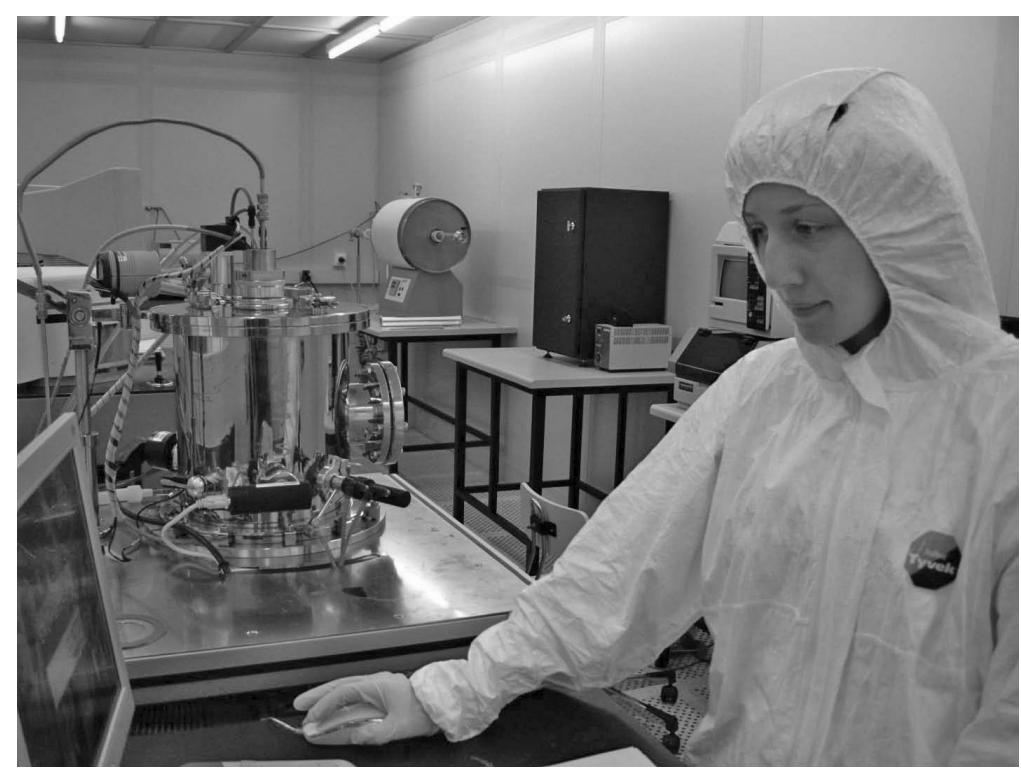

FIGURE 14.1 (See color insert)

An interior from the ARL facility at Bilkent University, Ankara.

quantum dots, and group four nanocrystals are just a few examples of the materials under study. The lab is also actively engaged in studies of photodetectors, lasers, plasmonics, and integrated optical devices (ARL, 2011). Figure 14.1 depicts the ARL facility at Bilkent University.

The Nanotechnology Research Center (NANOTAM) is a research center serving researchers from many departments of Bilkent University as well as other universities. Established in 2003, the center has 4,200 $\mathrm{m}^{2}$ of office and lab space, including clean rooms. Research areas in nanotechnology include nanophotonic crystals, photonic metamaterials, nanomaterials, nanoelectronics, nanoplasmonics, and nanotechnology-based solar cells (NANOTAM, 2011). Figure 14.2 depicts the NANOTAM facility at Bilkent University.

UNAM, the National Nanotechnology Research Center, was established in 2006, initially with funds primarily from the State Planning Agency. The center has $9,000 \mathrm{~m}^{2}$ of office and lab space, including clean rooms, serving researchers from within and outside Bilkent University. Research areas include nanobiotechnology, nanotextiles, nanochemistry, nanoelectronics, nanophotonics, and energy (UNAM, 2011). Figure 14.3 depicts the UNAM facility at Bilkent University.

Many other nanotechnology research centers exist in Turkey. Among these, we mention the Central Laboratory at the Middle East Technical University (METU), which is home to the Micro and Nanotechnology Program at the same university. Major research subjects include nanophotonics, optoelectronics, nanoelectronics, nanomagnetism, nanomaterials, nanofabrication, 


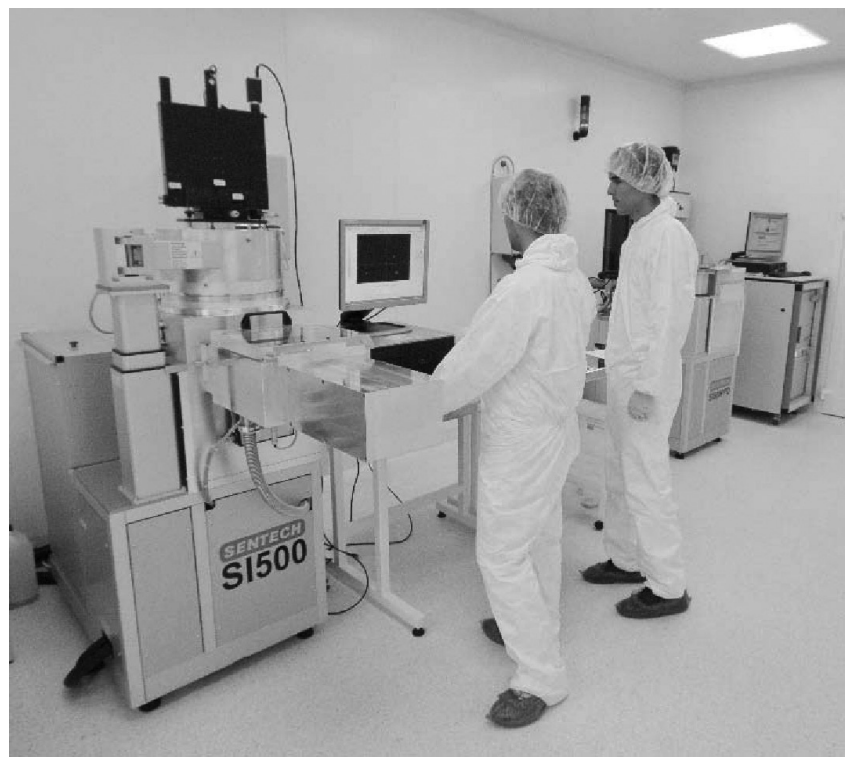

FIGURE 14.2 (See color insert)

The Nanotechnology Research Center (NANOTAM) facility at Bilkent University, Ankara.

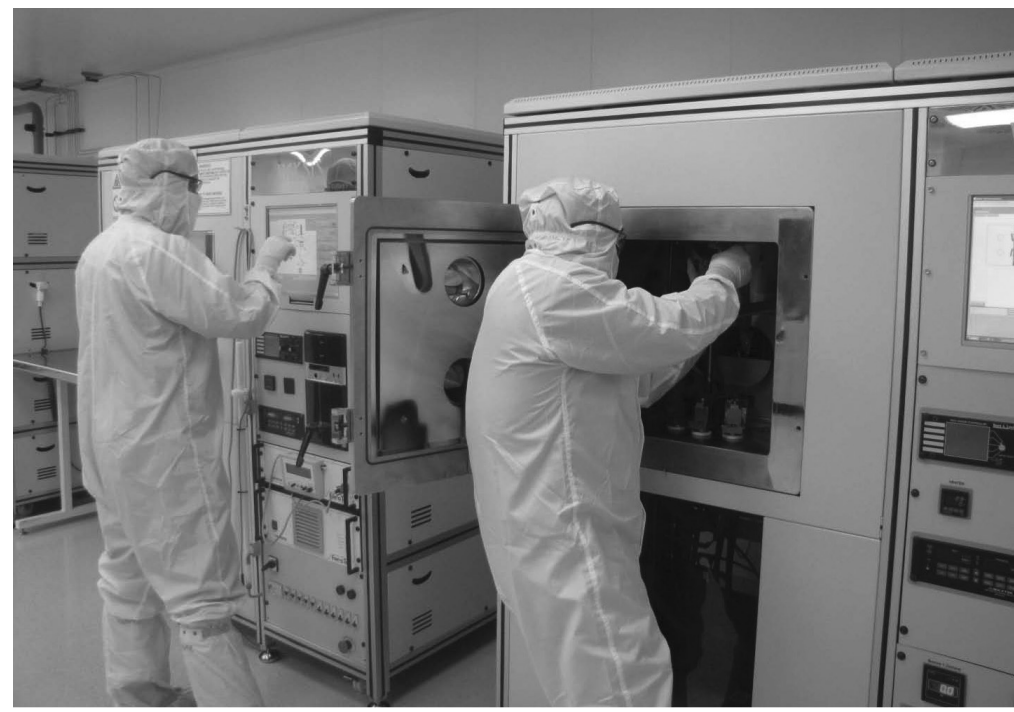

FIGURE 14.3 (See color insert)

The National Nanotechnology Research Center (UNAM) facility at Bilkent University, Ankara. 
and nanobiotechnology (METU, 2011a, 2011b). Also at Middle East Technical University is MEMS, the Micro-Electro-Mechanical Systems Research and Application Center. While not specifically dedicated to nanotechnology research, MEMS heavily serves the nanoscience and nanotechnology community from many institutions with its extensive facilities (METU-MEMS, 2011). The history of both centers goes back about twenty years.

SUNUM, the Sabanci University Nanotechnology Research and Application Center, supports research programs spanning biology, electronics, physics, chemistry, materials, and mechatronics. Research areas include advanced materials, nanobiotechnology, nanomedicine, nanoelectronics, nanomechanics, nanooptics, and alternative energy. The center, which started operations in 2011, has a 7,140- $\mathrm{m}^{2}$ building including clean rooms (SUNUM, 2011).

A common feature of many (though not all) nanotechnology centers in Turkey is that they have been primarily established within the last ten to fifteen years within universities, through State Planning Agency (DPT) infrastructure grants. These also include the Bionanotechnology Research Center at Fatih University, Istanbul; the Nanomedicine Research Center at Gazi University, Ankara; the Nanotechnology Research Centers at Gebze Institute of Technology, Gebze; and Istanbul Technical University, Istanbul, as well as SUNUM and UNAM already mentioned (DPT, 2010).

It should be noted that the establishment of dedicated research centers through State Planning Agency grants is not unique to nanoscience and nanotechnology, but seems to be a particular pattern resulting from the lack of more diverse sources of funding. The Scientific and Technological Research Council of Turkey (TUBITAK), the other major funding body, mostly funds specific research projects, leaving the State Planning Agency as the major grantor for the establishment of infrastructure in the form of research centers. (However, nanotechnology research is also undertaken in some centers connected to TUBITAK [Wikipedia, n.d.] The Department of Defence, which is a potential source of funding for high-tech research, does not yet seem to have played a major role in funding nanotechnology research in Turkey. It may also be worth noting that neither funding bodies nor public policy bodies have come forth with very specific targets, goals, or policies regarding nanotechnology research, beyond establishing it as a priority area.

Overall, it could be said that the state of nanotechnology research in Turkey is similar to that of other high-tech research areas. While Turkey does not have a large volume of research and investment in this area, the existence of a number of particularly strong centers is noteworthy.

A number of major corporations in Turkey undertake nanotechnology research and development, but their numbers are limited. Large companies such as Arcelik (mostly home appliances), Dyo (paints), and Aselsan (electronics, especially military) have research and development operations on nanomaterials. Overall, the interest of industry in nanotechnology is not at a very high level, with more watching than action. Most companies do not 
yet feel sufficient competitive pressure to become heavily involved in nanotechnology. Likewise, interaction between academia and industry is not very strong. Neither is the number of startups in research parks doing nanoscience or nanotechnology very high.

\section{Ethical and Social Issues Education}

Most practicing researchers, in all areas and in all countries, do not have any direct interest in ethical and social issues related to the research they are undertaking and the technology they are developing. While most researchers are conscientious about doing their research in an ethical manner (research ethics), they are not directly involved in discussions about ethical and social issues regarding the applications of the technology. One reason for this is insufficient exposure to the general background and conceptual and intellectual tools that would support such involvement.

Such exposure is not only important for researchers, but also for practicing engineers and professionals. Based on this understanding, ethical and social issues education is offered to and compulsory for all undergraduate engineering majors at Bilkent University. The main vehicle to this end is the course Science, Technology, and Society (Bilkent University, 2011b), which was initiated in 1995 . The course is now taken by about 500 students every year. It is a course of wide breadth covering a diversity of topics and teaching methods, and is probably the first course in Turkey to deal with the implications of ethical, social, cultural, political, economic, legal, environment and sustainability, health and safety issues, and the reliability dimensions of science, technology, and engineering.

During the early 1990s, gaining ABET (Accreditation Board for Engineering and Technology) (ABET, 2011) accreditation became a goal for elite universities in Turkey. Until that time, the need for incorporating ethical or social dimensions courses in engineering programs had not been felt by most institutions in Turkey. The present course was established at that time, and since then it has been the key course in meeting ABET requirements on ethical and social dimensions.

The course is broadly designed and covers a very wide array of subjects. The topics and contents have changed significantly over the years. The current syllabus has a current-issues focus and emphasizes subjects students would be familiar with from the media with the hope that they will be able to more easily relate to such topics:

- Ethics and technology

- Political positions and science and technology issues 
- Energy

- Ecology

- Population

- Health and technology

- Technology and the third world

- Future technologies

- Intellectual property

- Copyrights, patents, and trade secrets

- Philosophical aspects of artificial intelligence

- Technological disasters

- Responsibilities of scientists and engineers

- Technology decisions and the democratic process

Additional topics are covered through guest seminars and video presentations. The texts that are presently used are Technology and Society: A Bridge to the 21st Century (Hjorth, Eichler, Khan, \& Morello, 2003) and Taking Sides: Clashing Views in Science, Technology, and Society (Easton, 2008).

Many science and engineering departments that seek to meet educational or accreditational objectives choose to implement courses such as "Science and Ethics" or "Engineering Ethics." These courses usually consist of an introduction to ethical theories followed by case studies. While there is nothing wrong with this approach per se, such courses usually do not cover the diverse manifestations of the interaction of science, technology, and society in a more multidisciplinary fashion. Thus the choice at Bilkent University has been in favor of a "Science, Technology, and Society" studies approach. Further discussion of the philosophy and rationale behind the course design may be found in Ozaktas, 2010, 2011.

In its early years, the course was offered to about 150 or so computer-electrical-industrial engineering students. However with a threefold increase in admissions, the course now has nearly 500 students, and with the addition of a new Mechanical Engineering Department will exceed this number. This increase has necessitated the elimination of term papers/projects and small group discussions and the adoption of teaching techniques suitable for large classes. These include assigning debate topics to groups of students, who are expected to compose arguments for or against certain positions on a controversial topic. Selected opposing groups debate on stage in front of the whole class. The large audience also requires considerable stage performance and techniques of mass voting and collective opinion forming to involve the class as much as possible. The large number of students is far from ideal, but teaching it to smaller classes would entail a significant cost, which at present excludes this option. 
Various novel project concepts have been developed throughout the history of the course, including Web-based projects and the incorporation of the concept of "community research," which in contrast to "high technology" and "big science" (research heavily funded by governments and corporations and practiced by professional scientists), involves communities in the identification of their problems (such as public health and social issues) and encourages their participation in applying the results to directly improve their lives.

We all know the close relationships between sciences, technology, industry, and the economy. When people speak of science today, what comes to mind are usually big and expensive projects that have captured the imagination: space exploration, chemicals and pharmaceuticals, electronics and information technology, and the human genome project. As greater and greater wealth is being poured into such research, the discontent felt by ordinary people increases. They are at the same time impressed and disillusioned by the exponential progress, which despite the many conveniences it brings, somehow falls short of solving what they feel to be their real and immediate problems, and improving their conditions. Community research projects aim to directly address these needs and problems, and can potentially have empowering benefits for communities. For additional information about community research and related concepts such as grassroots science and science shops, we refer the reader to an article by Hansen (2005) and the websites of the Loka Institute (2011) and Living Knowledge (2011).

It is hoped that such courses dedicated to the ethical and social issues surrounding science and technology, along with general education courses in the social sciences and humanities, will provide scientists and engineers with the intellectual foundations that will make them more interested in and better able to deal with ethical and social issues pertaining to their area of research or practice. Interest and involvement of researchers and practitioners in these aspects of their subjects are also important for more meaningful discussion of these issues to take place among the general public. This, in turn, would hopefully lead to more democratic decision making regarding science and technology policies.

\section{Questions}

1. Compare and contrast the research areas of the various nanotechnology research centers in Turkey.

2. What are the common features of most nanotechnology centers in Turkey?

3. How is nanotechnology research funded in Turkey?

4. Comment on the interest of industry in nanotechnology in Turkey.

5. Why are most nanotechnology researchers not very interested in ethical and social issues relating to nanotechnology? 
6. State three important features of the course Science, Technology, and Society at Bilkent University.

7. Why was a "Science, Technology, and Society" approach preferred over an "Engineering Ethics" approach at Bilkent?

8. What are some of the benefits of community-research-type projects in education?

9. Summarize your learning of new ideas and information presented in this chapter by completing the following flowchart:

Flow Chart

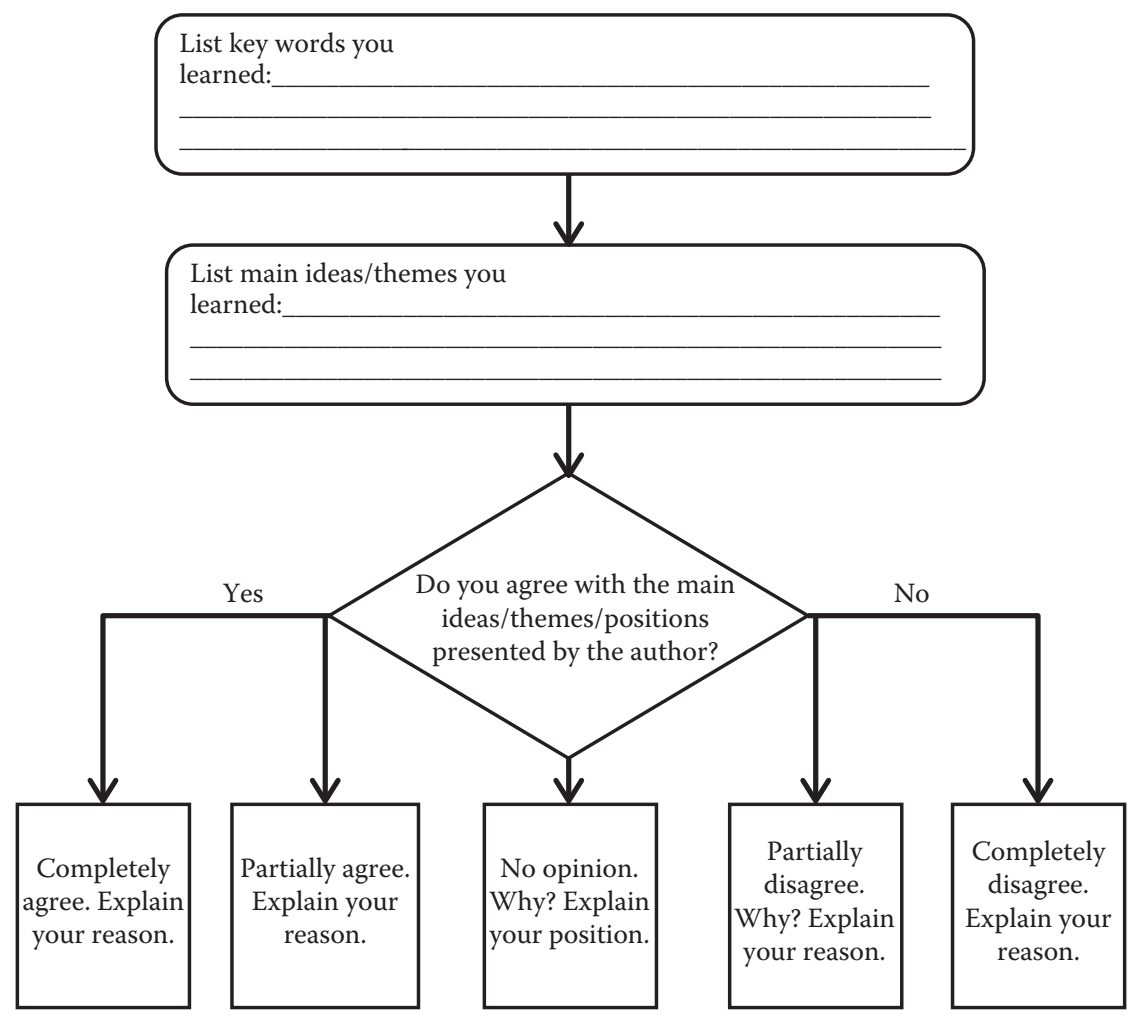

\section{Acknowledgment}

The author acknowledges partial support of the Turkish Academy of Sciences. 


\section{References}

ABET (Accreditation Board for Engineering and Technology). (2011). Home page. Retrieved September 28, 2011, from http:/ / www.abet.org

ARL (Advanced Research Laboratories). (2011). Home page. Retrieved September 28, 2011, from http:/ / arl.bilkent.edu.tr

Bilkent University, Ankara. (2011a). Home page. Retrieved September 28, 2011, from http://www.bilkent.edu.tr

Bilkent University, Ankara. (2011b). Course syllabus for GE 301: Science, Technology, and Society. Bilkent University, Ankara, Turkey. Retrieved September 28, 2011, from http:/ / www.ee.bilkent.edu.tr/ ge301

DPT (State Planning Agency, Ankara). (2010, December). University and Public Institutions Research Centers (in Turkish). Retrieved September 28, 2011, from http:/ / www.dpt.gov.tr /DocObjects /View /10120/Universite_ve_Kamu_ Kurumlari_Arastirma_Merkezleri.pdf

Easton, T. (2008). Taking sides: Clashing views in science, technology, and society (8th ed.). New York, NY: McGraw-Hill.

Hansen, T. B. (2005). Grassroots science: An ISYP Ideal? ISYP Journal on Science and World Affairs, 1, 61-72.

Hjorth, L. S., Eichler, B. A., Khan, A. S., \& Morello, J. A. (2003). Technology and society: A bridge to the 21st century (2nd ed.). Upper Saddle River, NJ: Prentice-Hall.

Living Knowledge: The International Science Shop Network. (2011). Home page. Retrieved September 28, 2011, from http:/ / www.scienceshops.org

Loka Institute. (2011). Home page. Retrieved September 28, 2011, from http:/ /www. loka.org

METU (Middle East Technical University). (2011a). Home page for Central Laboratory. Retrieved September 28, 2011, from http:/ / www.centrallab.metu.edu.tr

METU (Middle East Technical University). (2011b). Micro and Nanotechnology Program. Retrieved September 28, 2011, from http:/ / www.mnt.metu.edu.tr

METU-MEMS (Micro-Electro-Mechanical Systems Research and Application Center, Middle East Technical University). (2011). Home page. Retrieved September 28, 2011, from http://mems.metu.edu.tr

NANOTAM (Nanotechnology Research Center). (2011). Home page. Retrieved September 28, 2011, from http:/ / www.nanotechnology.bilkent.edu.tr

Ozaktas, H. M. (2012). Teaching science, technology, and society to engineering students: A sixteen-year journey. Science and Engineering Ethics, in print.

SUNUM (Sabanci University Nanotechnology Research and Application Center). (2011). Home page. Retrieved November, 2011, from http:/ / sunum.sabanciuniv.edu

UNAM (National Nanotechnology Research Center). (2011). Home page. Retrieved September 28, 2011, from http:/ / nano.org.tr

Wikipedia. (n.d.). Nanotechnology (in Turkish). Retrieved September 28, 2011, from http:/ / tr.wikipedia.org/wiki/Nanoteknoloji 